REVIEW

\title{
Developing your teaching style: increasing effectiveness in healthcare teaching
}

\author{
Kay Mohanna, Ruth Chambers, David Wall
}

Postgrad Med J 2007;83:145-147. doi: 10.1136/pgmi.2006.054106

This paper reports the first stage in the development of a tool, the Six Staffordshire Teaching Styles Questionnaire, designed to raise awareness in teachers about their teaching style. Effective teachers are adaptable and flexible in providing variety in their teaching activities, aiming to match their manipulation of the teaching and learning environment to the needs of the learner, but teachers should also know what type of activities they are most effective at delivering. Just as mismatched learning styles can cause dysfunctional learning situations, one of the causes of stress in teachers can be an incongruency between the type of activities they believe are effective, or feel they are good at carrying out, and external expectations of "good teaching".

See end of article for authors' affiliations

Correspondence to: Dr Kay Mohanna, Staffordshire University, Faculty of Health, Blackheath Lane, Stafford ST14 OAD, UK; Kaymohanna@aol.com

Received 2 October 2006 Accepted 4 December 2006
$\mathrm{T}$ his paper describes the Six Staffordshire Teaching Styles questionnaire. Insight into their preferred teaching styles might help novice teachers' professional development as they think about flexibility in provision of learning opportunities and also give them a way of thinking about dysfunctional teaching.

\section{BACKGROUND}

Recommendations to novice healthcare teachers about effective teaching of the "how to do it" variety tend to be based on the obvious ("prepare well"), personal opinion ("this is how I do it") and faith ("trust me, I'm a teaching expert"), rather than looking to see whether we can detect any common themes in the behaviours of the teachers of those learners who are achieving, or indeed, mapping those recommendations against any measures of learning or student progress.

Part of the reason for this is that it is very hard to be certain what actually does influence students' learning. Despite a wealth of literature, both opinion and evidence, on cognitive styles, the psychology of learning and how information is processed and activated in learning situations, ${ }^{1-4}$ there is still a leap of faith required to be sure of the extent to which teachers can positively influence that learning journey. Transfer into clinical practice and impact on patient care are long-term outcomes of teaching in clinical settings and many factors can have an effect along the way.

On the other side of the coin it is well recognised, at least by learners, that "bad" teaching can get in the way of learning. It is all too easy to demotivate learners and reduce their confidence and trust in themselves as learners. Inexpertly handled remedial interventions at times of dawning "conscious incompetence" (perhaps a failed exam or a patient complaint) can reinforce the feeling of worthlessness and a disinclination to persevere with learning. Those moving towards "unconscious incompetence" from a previous position of expertise, perhaps through ill health or rapidly changing work environment, also need sensitive guidance from expert teachers and mentors. It is easy to see how we could make things worse rather than better if we are clumsy in our feedback skills as we draw attention to their deficiencies. ${ }^{5}$

Whether we subscribe to theories that stress the importance of curriculum alignment or sequencing in teaching or emphasise constructivism or discovery learning - those that consider teachers to be managers and directors of learning, or those that state teachers are best employed as facilitators of learning-it is clear that teachers have a role in student progress.

"It would seem less than useful for a teacher to stand by and leave [a learner] alone in his enquiries, hoping that something will happen. ${ }^{\prime \prime 6}$

Indeed, some of the early experiments with implementing a problem based learning approach to medical undergraduate curricula may have unwittingly discovered just that.

There are some basic principles, derived predominantly from expert opinion but also from outcomes based evaluation, that tend to be repeated as elements of effective teaching:

- set clear goals and expected outcomes

- provide adequate supervision and assessment against these goals

- provide meaningful feedback

- show concern for students' progress.

Over the past 25 years, work has been done on these areas to link students' opinions about the presence or absence of these factors in their teachers with subsequent development of clinical skills. $^{7}$

Such work, however, tends to be concentrated on "what to do" rather than on "how to do it". Developing competency as expert teachers requires us to analyse and reflect on how we carry out tasks.

Effective teachers match teaching with the levels of expertise of the learner, a consideration of whether theoretical or practical educational material is being taught, and the purpose and context of learning. This adaptability is a key skill of a flexible 
teacher and is demonstrated as differences in teaching style.

Teaching style has been defined by Kathleen Butler as:

\begin{abstract}
"A set of attitudes and actions that open a formal and informal world of learning to the student. It is a subtle force that influences access to learning and teaching by establishing perimeters around acceptable learning procedures, processes and products. It is the powerful force of the teacher's attitude to the student as well as the instructional activities used by the teacher and it shapes the learningteaching experience. ${ }^{1 / 8}$
\end{abstract}

We have constructed a model of teaching styles derived both from a theoretical consideration of what the constituent factors of teaching style are and empirical findings from healthcare teachers.

\section{METHODS}

We undertook an electronic literature search of PubMed, EMBASE, CINAHL and ERIC databases and further hand searching in 2004. Search terms included: doctor, peer review, competence, capability, competency, education, teaching, training, teaching styles. We confined the literature to that specifically relating to healthcare teachers. Two researchers independently verified whether the 1600 or so abstracts resulting from the literature search were relevant and if the full papers obtained were specific to the study aims. We extracted all descriptions of any aspects of teaching styles or delivery of a healthcare teacher from published papers assessed as being relevant.

Following a review of the literature we drew up a list of descriptive terms for a variety in teaching style. These key aspects were used as the basis of a list of paired questions to help define these differences. A period of consultation with fellow health teachers then followed and this refined the questions until we were sure that all themes that could be considered to be part of a definition of teaching styles were included. A 96 item questionnaire with a $1-5$ Likert scale answer format was devised. We sent this to all 132 medical and dental teachers on the West Midlands Deanery database.

A total of 88 questionnaires were returned (67\%). The results were analysed using SPSS, using reliability analysis and principal component factor analysis. Reliability was very good with an overall Cronbach's $\alpha$ of 0.901 . There were no questions which stood out as being of poor reliability using the "alpha if item deleted" function in the calculations of reliability. Exploratory factor analysis using principal component factor analysis, with varimax rotation and with Kaiser normalisation, was used. The number of factors accepted is a matter of debate and of judgement.' The Kaiser criterion, accepting all factors with an Eigen value of above 1.0, would have given 26 different factors. ${ }^{10}$ Clearly this would not have taken us much further in determining a small number of styles. Instead, the method described by Cattell ${ }^{11}$ was used, using a scree plot and determining the number of factors by the inflexion point in the scree plot curve, and accepting all factors above that point. ${ }^{11}$ This inflexion point was achieved with six factors, and setting SPSS to accept these six factors produced a convergence in 12 iterations. All Eigen values for all these factors were above 3.0, when the curve levelled out into "scree". The other test is that the final factors and the factor content "made sense". We think that the factor content and the factors themselves have high face validity.

So, exploratory factor analysis showed six factors, which were clearly identifiable with different teaching styles. These six styles were then described using free text descriptors from the key.
RESULTS

The six teaching styles

- The all round flexible and adaptable teacher-This teacher can effectively use lots of different teaching activities, is comfortable teaching both peers and juniors, and is very aware of the way the whole environment affects both teachers and learners.

- The sensitive, student centred teacher-This teacher is very student centred, prefers teaching in small groups, with emotions to the fore using role play and drama, and is not comfortable doing straight presentations.

- The official formal curriculum teacher-This teacher is very well prepared as a teacher, likely to be accredited, is very aware of and teaches to the formal curriculum, and follows external targets for teaching.

- The straight facts, no nonsense teacher-This teacher likes to teach well defined facts, with straight talking, concentrating on specific skills, and much prefers not to be involved with multi-disciplinary teaching and learning.

- The big conference teacher-This teacher likes nothing better than to stand up in front of a big audience. This teacher does not like sitting in groups or one to one teaching.

- The one-off teacher-This teacher likes to teach small self contained bits of teaching, often ad hoc and on a one to one basis, with no props to help and no follow up.

Each of the six Staffordshire teaching styles is here described by a single sentence. This encapsulates the style which is itself, however, derived from answers to a variety of questions.

Having empirically derived these six discrete styles by selfassessment, work is now ongoing to test them out in the clinical setting by direct observation of teaching rather than self report, looking to match adoption of a particular style with students outcomes in varying teaching arenas. This work will be reported elsewhere.

\section{DISCUSSION}

So what influences which teaching style a teacher adopts? There is some evidence that choice of teaching style is one facet of a teacher's general view about the purposes of education. We can describe two categories of teachers, formal and informal. Formal teachers see their role in terms of the dominance of outcomes such as examination results, demonstration of predetermined competencies and vocational training. These teachers tend to favour a structured approach. Informal teachers stress learners' enjoyment of education and opportunities for self-expression and tend to favour discovery learning.

A formal teacher, if asked to identify how to measure an effective teacher, might be inclined to list classroom attributes such as orderliness, adherence to rules and student attentiveness, and stress the importance of knowledge base, preparation of lesson plans and handouts and clarity in setting objectives.

An informal teacher asked the same question might tend to list student attributes such as spontaneity of students responses, enthusiasm in learners, individuality of contribution.

Field-dependent learners, those who tend to be more informal, may prefer their teachers to be more discursive in their teaching style. They are at risk of feeling less comfortable with a more convergent, structured approach. Similarly fieldindependent learners, who tend to be more structured in their approach, might be less comfortable with discussion-based or divergent methods.

Flexible teachers not only have to be able to understand and teach in both ways, they need to be able to understand barriers to effective learning that such differences in cognitive styles can raise if not acknowledged. 


\section{CONCLUSION}

One of the keys to effective teaching is flexibility. Having derived descriptors for six discrete teaching styles, we have developed a questionnaire based self assessment tool (SETS, The Staffordshire Evaluation of Teaching Styles questionnaire ${ }^{\Theta}$ ) that may be useful in teacher-training. Learner difference is only one factor in the teacher-learner dyad and teacher difference also needs to be taken into account.

\section{Authors' affiliations}

Kay Mohanna, West Midlands Deanery, and Staffordshire University, Faculty of Health, Stafford, UK

Ruth Chambers, David Wall, NHS West Midlands Workforce Deanery, Edgbaston, Birmingham, UK

Competing interests: none declared.

\section{REFERENCES}

1 Entwistle NJ. Styles of teaching and learning. London: David Fulton Publishers, 1988.

2 Honey P, Mumford A. Using your learning styles. Maidenhead: Peter Honey, 1986.

3 Kaufman DM, Mann KV, Jennett PA. Teaching and learning in medica

education: how theory can inform practice. Edinburgh: ASME, 2000

4 Kolb DA. Experiential learning: experience as the source of learning and development. Englewood Cliffs, NJ: Prentice Hall, PTR, 1984.

5 Mohanna K, Wall D, Chambers R. Teaching made easy, 2nd ed. Oxford: Raddlife, 2003

6 Bennett SN. Teaching styles and pupil progress. London: Open Books, 1976

7 Petzel RA, Harris IB, Masler DS. The empirical validation of clinical teaching strategies. Evaluation and the Health Professions 1982;4:499-508.

8 Butler KA. Learning and teaching style in theory and practice. Connecticut: The Learner's Dimension, 1984.

9 Field A. Discovering statistics using SPSS for Windows. London: Sage Publications Ltd, 2000.

10 Kaiser HF. The application of electronic computers to factor analysis. Educational and Psychological Measurement 1960;20:141-51.

11 Caftell RB. The scree test for a number of factors. Multivariate Behavioural Research 1966;1:245-76.

\section{bmjupdates+}

bmjupdates+ is a unique and free alerting service, designed to keep you up to date with the medical literature that is truly important to your practice.

bmjupdates+ will alert you to important new research and will provide you with the best new evidence concerning important advances in health care, tailored to your medical interests and time demands.

\section{Where does the information come from?}

bmiupdates+ applies an expert critical appraisal filter to over 100 top medical journals A panel of over 2000 physicians find the few 'must read' studies for each area of clinical interest

Sign up to receive your tailored email alerts, searching access and more...

www.bmjupdates.com 